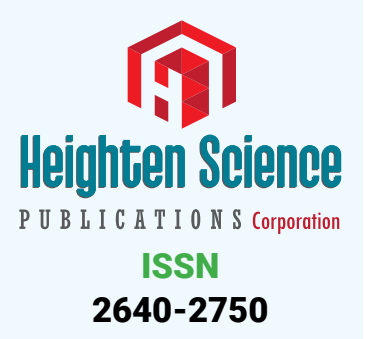

*Address for Correspondence: Lychkova AE, MD, Head of Department of Moscow's Clinical Scientific Center, Moscow Health Department, 86 Enthusiastov sh., Moscow, 111123, Russia, Tel: 8-962-965-4923; Email: lychkova@mail.ru

Submitted: 28 July 2017

Approved: 24 August 2017

Published: 25 August 2017

Copyright: @ 2017 Lychkova AE, et al. This is an open access article distributed under the Creative Commons Attribution License, which permits unrestricted use, distribution, and reproduction in any medium, provided the original work is properly cited.

Keywords: Rat; Pancreatic duct; Motor function; Pancreatitis; Infliximab

Check for updates
Research Article

\section{The influence of Infliximab on the development of Experimental Pancreatitis}

\author{
Lychkova $\mathrm{AE}^{1 *}$, Golubev $\mathrm{Yu} \mathrm{Yu}^{2}$ and Puzikov $\mathrm{AM}^{3}$ \\ ${ }^{1}$ Head of department of Moscow's Clinical Scientific Center, Moscow Health Department, \\ Russia \\ ${ }^{2}$ Associate professor, department of propaedeutics Russian National Research Medical \\ University named after N.I. Pirogov, Russia \\ ${ }^{3}$ Collaborator, department of Moscow's Clinical Scientific Center, Moscow Health Department, \\ Russia
}

\section{Abstract}

Aim: To identify the possibility of correction of motor function of the gastro-intestinal tract in experimental pancreatitis with the administration of infliximab.

Material and methods: Pancreatitis was modeled by the administration of picrylsulfonic acid retrogradely into the pancreatic duct of rat $(n=5)$ and 4 animals were control. Electromyogram (EMG) of the pancreatic duct was monitored immediately after the administration of picrylsulfonic acid and on the 15th day of pancreatitis simulation before and after the administration of infliximab. The morphological investigation of pancreas was conducted on the 15th day of development of pancreatitis and on the 15th day of treatment of pancreatitis with infliximab.

Results: Infliximab restores the motor function of pancreatic duct and structure of pancreas during acute pancreatitis.

Conclusion: Protective action of infliximab during acute pancreatitis was shown.

\section{Introduction}

Acute pancreatitis is an inflammatory response to pancreatic injury mediated by tumor necrosis factor alpha (TNF-a) [1]. Infliximab (trade names Remicade et al.) is a chimeric monoclonal antibody biologic drug that induced the lysis of the TNF-a producing cells. Monoclonal antibodies against TNF $\alpha$, including infliximab, adalimumab, golimumab, and certolizumab pegol, are widely used for the treatment of the inflammatory diseases such as rheumatoid arthritis and inflammatory bowel disease. Recently, the crystal structures of TNF $\alpha$, in complex with the Fab fragments of infliximab and adalimumab, have revealed the molecular mechanisms of these antibody drugs [2].

Acute pancreatitis is a severe disease with high mortality. Clinical studies can bring some data about etiology, pathogenesis and the course of acute pancreatitis. However, studies concerning early events of this disease and the new concepts of treatment cannot be performed on humans, due to ethical reasons. Animal models of acute pancreatitis have been developed to solve this problem [3]. In recent years, a number of articles have been published on the treatment of acute pancreatitis in experimental models [4]. It is known disturbance of propulsive activity of gastro-intestinal tract during pancreatitis [5]. Administration of infliximab for treatment of pancreatitis, in connection with the disturbance of this activity, by method electromyography was insufficiently studied [6]. Aim-to identify the possibility of correction of motor function of the gastro-intestinal tract in experimental pancreatitis by the application of infliximab. 


\section{Materials and Methods}

\section{Animals}

The study was carried out at Moscow's Clinical Research Center of Health Department, Moscow, Russia. Female Wistar rats weighing from 210 to 230 g were obtained from State Scientific Institution Center for Biomedical Technologies, Moscow region, Russia. Before the experiment, the animals were fed with standard rat portions and water optional and housed in metabolic cages at constant temperature and 12-h light/dark cycles. Food was withdrawn $12 \mathrm{~h}$ before experiment. The experiment was approved by the Institutional Animal Use and Care Committee of the Moscow's Clinical Research Center, Moscow, Russia.

\section{Experimental model of acute pancreatitis}

Anesthesia was induced with Nembutal inhalation. Laparotomy was performed through a high midline incision. The pancreatic duct was cannulated. Then, pancreatitis was modeled by the retrograde infusion of $0.1 \mathrm{ml}$ of picrylsulfonic acid in 1:1 ratio with $96 \%$ ethyl alcohol into the pancreatic duct. After the infusion, the abdomen was closed in two layers. All procedures were performed using sterile techniques.

\section{Study protocol}

After the stabilization period, 14 female rats were divided into three groups. Groups 1 and 2 underwent induction of acute pancreatitis. Group 1 (pancreatitis plus saline, $n=5$ ) received saline injection $(10 \mathrm{ml} / \mathrm{kg}$, ip) whereas group 2 (pancreatitis plus infliximab, $n=5$ ) received infliximab (Janssen Biotech, Inc., USA) (10 mg/kg injection for (0.125 ml, ip) 2-3 min until the administration of picrylsulfonic acid into the pancreatic duct. Group 3 (sham plus saline, $n=4$ ) underwent laparotomy with only manipulation of the pancreas.

\section{Electromyogram}

(EMG) of pancreatic duct was recorded using surface bipolar electrodes in control, directly after induction of pancreatitis and on the $15^{\text {th }}$ day of the simulation of pancreatitis.

\section{Testing of morphological severity of acute necrotizing pancreatitis}

Morphological investigation of pancreas was conducted on the $15^{\text {th }}$ day of pancreatitis development and on the $15^{\text {th }}$ day of pancreatitis development under the condition of preliminary administration of infliximab. The tissue samples were fixated in $9 \%$ formalin, dehydrated in alcohol of increasing concentration, enclosed in paraffin, histological slices were prepared and stained with hematoxylin and eosin.

\section{Statistical processing}

Statistical processing of obtained data was conducted with the application of packet program Statistica-6. All quantitative data, obeying the normal distribution, were presented using as mean $\mathrm{M} \pm \mathrm{m}$. For the processing of obtained data, criterion Student $(t)$ with the subsequent distinct level of reliability of differences ( $p$ ) and criteria $\chi^{2}$ was applied. The differences between average values were considered reliable when $\mathrm{p}<0.05$.

\section{Results}

The test frequency of EMA of pancreatic duct of intact rat was $10.3 \pm 0.8$ per min, amplitude-0.18 $\pm 0.012 \mathrm{mV}$.

The administration of picrylsulfonic acid led to the increase of EMA of pancreatic duct up to $13.7 \pm 1.6$ per $\min (33 \%$, $\mathrm{p}<0.05)$, with amplitude of $0.28 \pm 0.07 \mathrm{mV}(55.5 \%$, 
$\mathrm{p}<0.05)$. Besides that, the spikes activity with frequency of $2.0 \pm 0.1$ and amplitude of $0.21 \pm 0.011 \mathrm{mV}$ was observed. Thus, during the simulation of pancreatitis, an increase of frequency and amplitude of slow-wave and spikes activity is observed, which in general testifies about the increase of excitability of smooth muscle cells of the duct (Figure 1).

On the $15^{\text {th }}$ day of simulation of pancreatitis, the frequency of slow wave EMA of pancreatic duct was $10.9 \pm 0.9$ per min (decreased by $20.4 \%$ ), amplitude- $0.32 \pm 0.02$ $\mathrm{mV}$ (increased by 14.3\%). In 33\% of cases the spiked activity with average amplitude was determined, and, the frequency of spikes was $1.0 \pm 0.03$ in one slow wave $(-50 \%$, $\mathrm{p}<0.05)$, amplitude $-0.15 \pm 0.003 \mathrm{mV}(-28.5 \%, \mathrm{p}<0.05)$. These indicators testify about the preservation of high excitability of smooth muscle cells of duct on the $15^{\text {th }}$ day of pancreatitis.

Morphological investigation of pancreas, conducted 15 days after the administration of picrylsulfonic acid, revealed edema of lobules and a little increase of interlobular and intralobular connective tissue. Thin intralobular connective tissue layers were divided into a few group of cells. Unexpanded arteries and some expanded veins with the marginal standing of erythrocytes were located in the interlobular space. Most of the exocrinocytes contains zymogen granules. Some accumulations of destructed cells are located in a separated site of gland. Cells with changes of dystrophic characters are located in a separated site of gland: cytoplasm is vacuolated, secretory granules are absent, nucleus maintains normal structure or in different level is compacted. Destructively changed cells contain a little amount of zymogen granules. The density of endocrinocytes in islets was a little reduced: expanded spaces between cells, filled with connective tissue with single capillaries were detected. Capillaries were dilated (Figure 2).

Ducts contain homogeneous protein substance of different degree of density. Epithelium of the ducts is cubical. The nuclei of epithelial cells are large, clearly stained, with moderately aggregated chromatin, protrude into the lumen of ducts. Expanded veins and capillaries with single erythrocytes are located near to the excretory duct. Arteries are of usual diameter. Muscular membrane is thin, presented by some layers of smooth muscle cells.

The frequency of slow waves of electromotor activity of pancreatic duct on the 15th day of infliximab administration on the background of simulation of pancreatitis

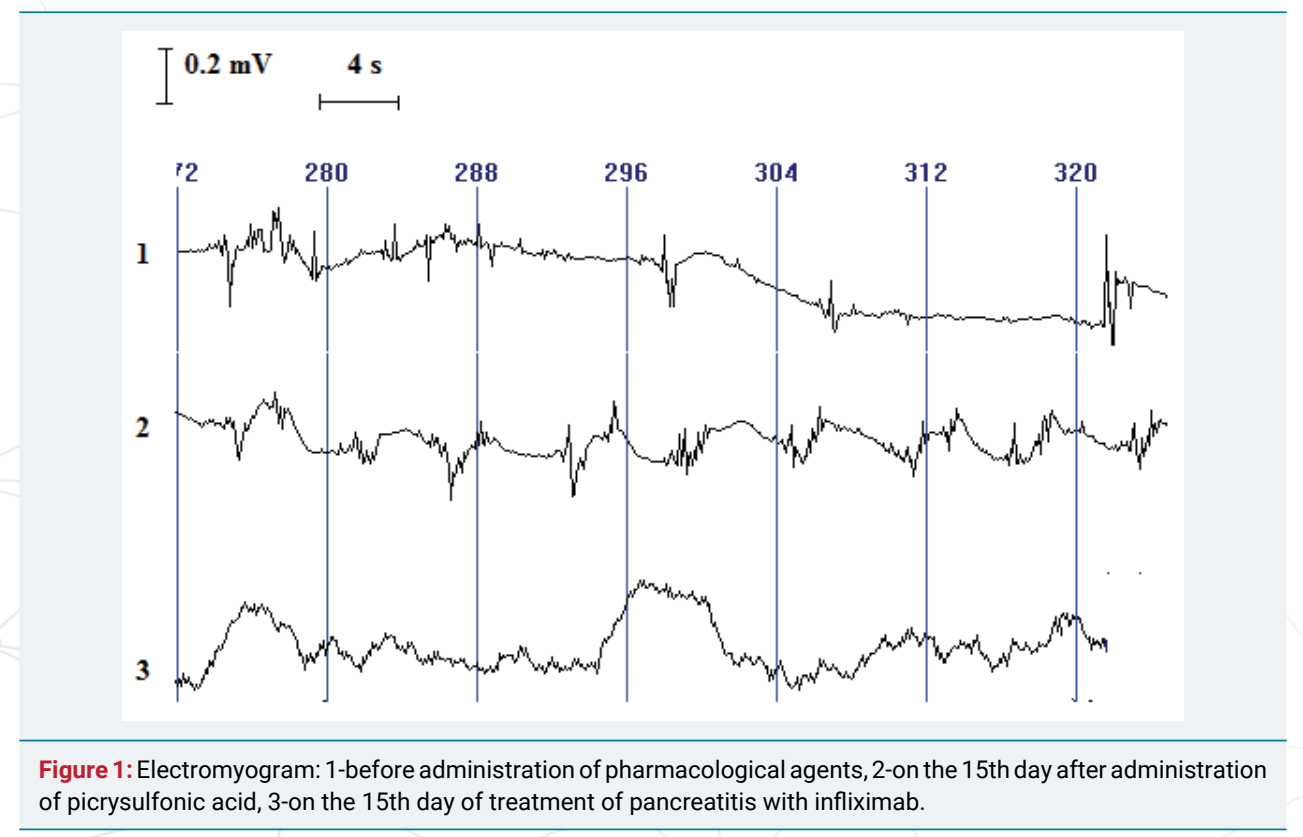




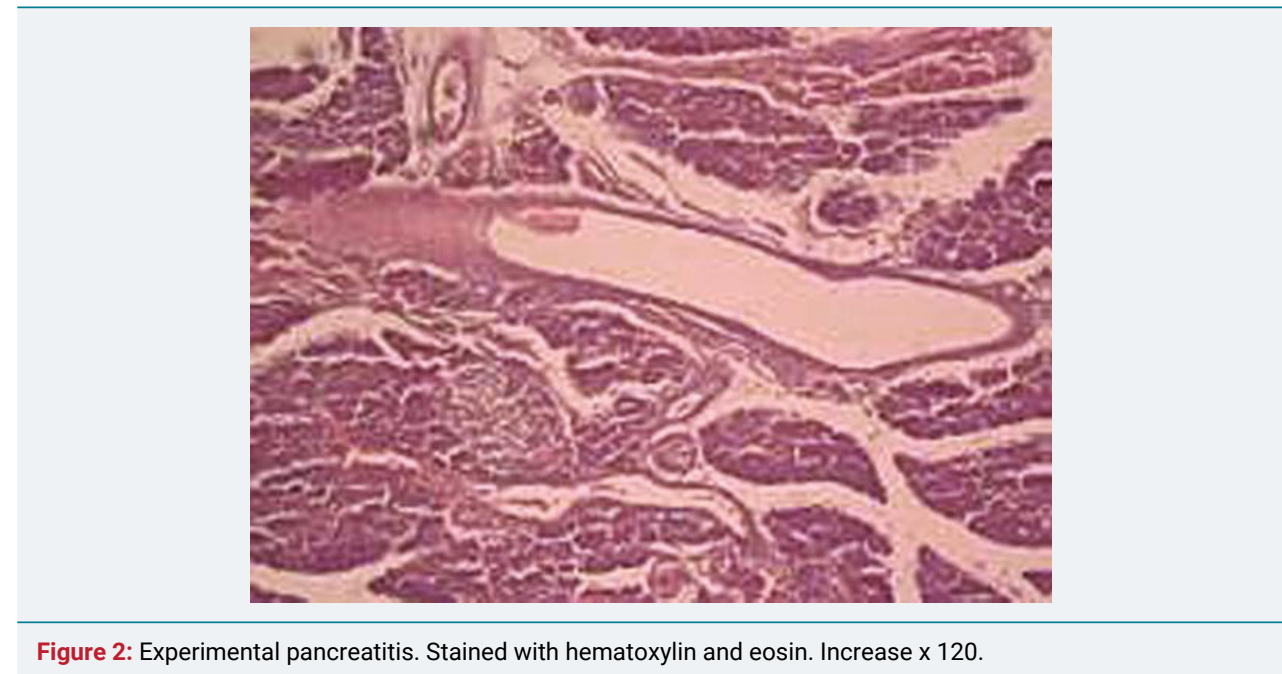

was $10.3 \pm 0.7$ per $\min (-5.5 \%, \mathrm{p}>0.05)$, amplitude $-0.21 \pm 0.02 \mathrm{mV}(-34.4 \%, \mathrm{p}>0.05)$; spiked activity was revealed in all observations, frequency was $2.3 \pm 0.2(129.9 \%$, $\mathrm{p}>0.05)$ and amplitude $0.18 \pm 0.02 \mathrm{mV}(20 \%, \mathrm{p}>0.05)$. That is, the contractile function of smooth muscle cells of duct during pancreatitis under the condition of infliximab administration is restored to the control level.

Morphological investigation of pancreas, conducted 15 days after the administration of picrylsulfonic acid on the background of infliximab action, revealed edema of a single lobe. Unexpanded arteries and insignificantly expanded veins with stasis of erythrocytes were located in the interlobular space. Exocrinocytes contain a little amount of zymogen granules. The density of endocrinocytes in the islets was a little reduced. Small ducts contain a small amount of protein homogeneous secretion (Figure 3).

\section{Conclusion}

Simulation of pancreatitis is accompanied by some increase of amplitude-frequency characteristics of pancreatic duct motor activity of the duct. The change of functional state of smooth muscle cells of ducts was accompanied by the destruction of part of exocrinocytes, accumulation of viscous secretion in small ducts of pancreas, which, together with the change of motor function of duct, may lead to the activation of proteolytic enzymes in the tissue of the gland itself with the possibility of development of its further destruction.

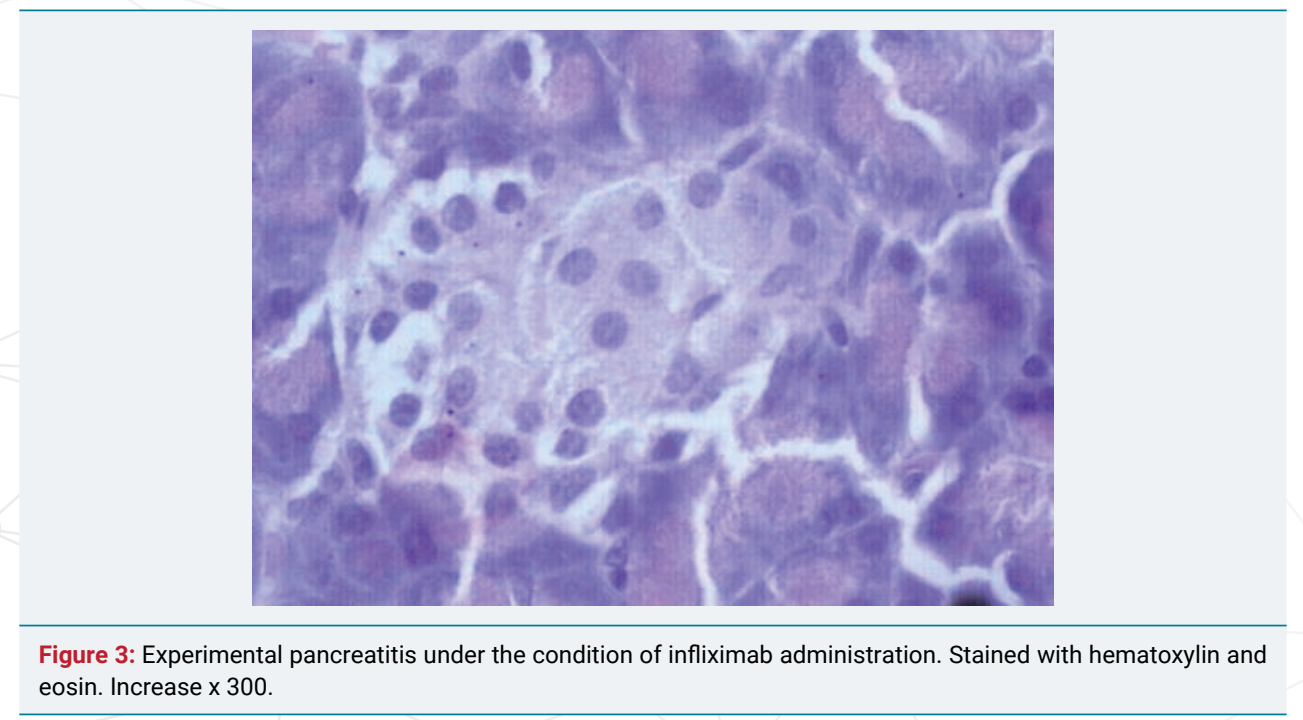


The administration of infliximab after 15 days of experiment normalizes the motor function of pancreatic duct. The normalization of motor function of smooth muscle cells of the pancreatic duct is accompanied by the reduction in the severity of edema of lobules and destruction of exocrinocytes, reduction of appearance of protein secretion in small ducts, which indicates the normalization of synthetic function of exocrinocytes and the restoration of outflow of pancreatic secretion.

Thus, the activation of motor function of pancreatic duct during pancreatitis under the condition of preliminary administration of infliximab does not lead to the development of very severe morphological changes in the structure of pancreas and its exocrinocytes; in the small ducts of pancreas the accumulation of viscous secretion, which impedes the outflow of pancreatic secretion into the duodenum is practically not detected. Infliximab provides the protective action in the development of pancreatitis.

\section{References}

1. Schäfer $C$, Tietz AB, Göke B. Pathophysiology of acute experimental pancreatitis: lessons from genetically engineered animal models and new molecular approaches. Digestion. 2005; 71: 162-172. Ref.: https://goo.gl/JWEVUq

2. Lee JU, Shin W, Son JY, Yoo KY, Heo YS. Molecular Basis for the Neutralization of Tumor Necrosis Factor a by Certolizumab Pegol in the Treatment of Inflammatory Autoimmune Diseases. Int J Mol Sci. 2017; 18: 228. Ref.: https://goo.gl/x4GARQ

3. Ou X, Cheng Z, Liu T, Tang Z, Huang W, et al. Circulating Histone Levels Reflect Disease Severity in Animal Models of Acute Pancreatitis. Pancreas. 2015; 44: 1089-1095. Ref.: https://goo.gl/sDEabp

4. Fantini L, Tomassetti P, Pezzilli R. Management of acute pancreatitis: current knowledge and future perspectives. World J Emerg Surg. 2006; 23: 1-16. Ref.: https://goo.gl/BrDMia

5. Ozhan G, Yanar HT, Ertekin C, Alpertunga B. Polymorphisms in tumor necrosis factor alpha (TNFalpha) gene in patients with acute pancreatitis. Mediators Inflamm. 2010; 2010: 482950. Ref.: https://goo.gl/h2ekXm

6. Maev IV, Kucheryavy Yu A. Drug therapy for chronic pancreatitis. News of medicine and pharmacy. 2007; 218: 14-16. 